\title{
Physicians' attitudes towards reproduction in young patients with early breast cancer in China
}

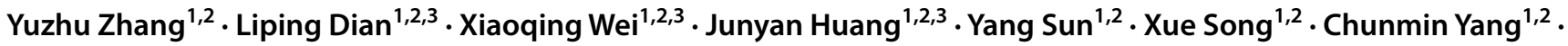 \\ Mengling Kang ${ }^{1,2} \cdot$ Aihua Ou ${ }^{1,2} \cdot$ Qianjun Chen ${ }^{1,2} \cdot$ Rui Xu $^{1,2,3}$ (1)
}

Received: 9 January 2020 / Accepted: 31 July 2020 / Published online: 10 August 2020

(c) The Author(s) 2020

\begin{abstract}
Background As more young patients with breast cancer undergo treatments and obtain good prognoses, the issue of postoperative reproduction in breast cancer patients has attracted more attention.

Methods We conducted a prospective, cross-sectional survey of 2000 breast cancer-associated physicians using a 24-items questionnaire adapted from prior guides. Then we used a multivariable linear regression model to confirm independent associations between the propensity of physicians' attitudes toward reproduction and physicians' specific demographic characteristics.

Results A total of 911/1249 (72.93\%) eligible physicians completed the questionnaire. Regarding the most concerning topic of whether breast cancer patients could conceive, 65 (7.1\%) physicians having low and 457 (50.2\%) physicians having high propensity for recommending reproduction. For ductal carcinoma in situ (DCIS) after surgery and radiotherapy, 599 $(65.8 \%)$ physicians did not agree with the recommendation to conceive. 231 (25.4\%) highly agree with the recommendation of reproduction for 2 years after surgery in invasive breast cancer patients with lymph nodes-negative. Only 140 (15.4\%) physicians did not agree with the recommendation for 5 years after surgery in invasive breast cancer patients with lymph nodes-positive. A total of 861 (94.5\%) physicians stated that they advised the patients to consult experts from other disciplines, such as gynecology, oncology, genetic and psychology disciplines. In multivariable analysis, more positive attitude toward reproduction was significantly associated with male, more than 11 times of participating in academic forum on breast cancer, 1-2 times of consulting about reproduction problems after breast cancer surgery per outpatient service and more than 11 min spending on solving the problem about reproduction in early breast cancer.

Conclusion This study showed that attitudes towards reproduction of young breast cancer patients from physicians in China. Physicians had a high propensity for recommending reproduction. Compared with the two reproduction guidelines recommendation when to reproduce in different circumstances for breast cancer patients, physicians from China remained a relatively conservative attitude. Most physicians advised the patients to consult experts from other disciplines, such as gynecology, oncology, genetic and psychology disciplines.
\end{abstract}

Keywords Attitudes $\cdot$ Physicians $\cdot$ Reproduction $\cdot$ Breast cancer $\cdot$ Young patients

Yuzhu Zhang, Liping Dian and Xiaoqing Wei have contributed equally to this work and should be considered co-first authors.

Qianjun Chen

cqj55@163.com

$\triangle$ Rui Xu

13524409346@163.com

1 Breast Department, Guangdong Provincial Hospital of Chinese Medicine, Guangzhou, China
2 The Second Affiliated Hospital of Guangzhou University of Chinese Medicine, Guangzhou, China

3 The Second Clinical College of Guangzhou University of Chinese Medicine, Guangzhou, China 


\section{Introduction}

Breast cancer has the highest incidence among female malignancies. A total of $0.5-2 \%$ patients is diagnosed with breast cancer before age 20, and approximately $20 \%$ are diagnosed before age 30 [1]. As more and more young breast cancer patients receive standardized treatments and a good prognosis, young patients' reproduction has been given more and more attention, especially because of the implementation of the Two-Child Policy in China. Patients with breast cancer are always advised to avoid becoming pregnant or to put off reproduction for at least 2 years after treatment, especially for luminal breast cancer, as reproduction would induce cancer recurrence and worsen survival [2]. However, some retrospective studies have contradicted the hypothesis that reproduction in breast cancer patients is safe and even has established benefits for the prognosis of patients [3-5]. Interestingly, Theriault et al. [4] found a $41 \%$ lower risk of death among women who became pregnant after a breast cancer diagnosis compared to women with no reproduction. In addition, Theriault [5] also showed that regardless of estrogen receptor status, there was no difference in diseasefree survival (DFS) between women who became pregnant after their breast cancer diagnosis and those who did not, and there was a benefit in overall survival (OS) among those who were pregnant. In fact, the study selection bias and research correlation index still need to be verified. Generally, that reproduction endangers breast cancer patient survival, especially in patients who are estrogen receptor (ER)-positive, remains controversial.

Although most young breast cancer patients still desire to conceive after systemic cancer therapy, the reproduction rate is $70 \%$ lower than that of the general population due to the reproductive decline caused by treatment, including gonadotoxic chemotherapy and endocrine therapy [6, 7]. reproduction occurring more than 1 year after the diagnosis of breast cancer did not appear to affect patient survival, and the appropriate time for patients to attempt pregnancies after undergoing breast cancer treatment is still not clear. The 2017 Rehabilitation Therapy Consensus on Breast Cancer in China [8] and the British Royal Society of Obstetrics and Gynecology [9] have given advice about reproduction according to the patients' clinic condition. This consensus intends to help relevant physicians guide young breast cancer patients with their fertility needs. However, we do not know the attitudes of breast cancer-associated physicians toward the postoperative reproduction of breast cancer patients.

Herein, to examine the attitude of breast cancer-associated physicians regarding reproduction after systemic cancer therapy, we designed a prospective attitude survey with specific clinical scenarios regarding reproduction in young patients with breast cancer according to the guides above.
The characteristics of the physicians with a relatively high propensity for recommending reproduction in the specific clinical context were analyzed.

\section{Methods}

\section{Sampling and data collection}

This analysis was derived from a prospective, cross-sectional study about breast cancer-associated physicians' attitude toward reproduction in early breast cancer patients, which was conducted from January 24, 2019, to June 20, 2019. To ensure that the investigators involved were breast cancer physicians, participants were from the Chinese Society of Clinical Oncology, Committee of Breast Cancer (CSCO$\mathrm{BC})$. We designed the questionnaire on 'Wenjuanxing' (https://www.wjx.cn) and distributed the questionnaire by WeChat.

Before the formal investigation, we conducted extensive pretesting. Then we chose $90 \mathrm{~s}$ as a screening criterion because it takes an average of $90 \mathrm{~s}$ for a partner of our research team to complete these questionnaires. If it is less than $90 \mathrm{~s}$, it means that he is likely to fill in the answers without fully reading the questions. The questionnaire content of this study mainly included 3 parts: (1) the collection of baseline information, (2) the evaluation of attitudes toward the scenario-based treatment strategy, and (3) attitudes about decision-making and associated risk factors. The study was approved by the ethics committee of GuangDong Provincial Hospital of Chinese Medicine (ZE2019-037).

\section{Measures}

To investigate the physicians' attitudes toward reproduction in young patients with early breast cancer, we designed 11 clinical scenarios. First, we used 4 questions to ask physicians whether a subsequent reproduction would alter patients' risk of disease recurrence and whether systemic cancer therapy would affect fetal health. The questions were as follows: (1) Do you think a patient with breast cancer can become pregnant? (2) Do you think reproduction has negative effects on breast cancer patients? (3) Do you think reproduction in early breast cancer patient has negative effects on the fetus? and (4) do you think patients can breastfeed after delivery? Second, we used 4 questions to determine the physicians' attitudes about the timing of reproduction after breast cancer treatment. The questions were as follows: (1) will you suggest patients with breast cancer become pregnant in situ after surgery and radiotherapy? (2) Will you suggest invasive breast cancer patients who are lymph nodenegative become pregnant 2 years after surgery? (3) Will you suggest invasive breast cancer patients who are lymph 


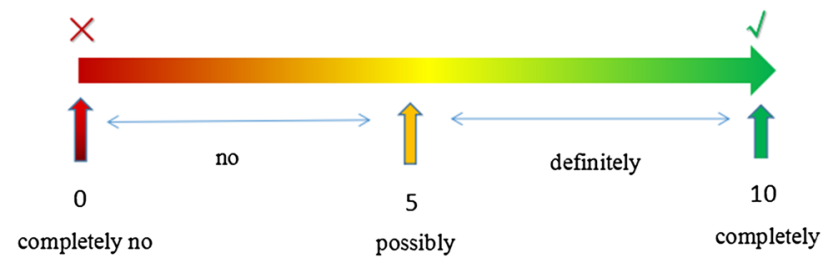

Fig. 1 The visual selection diagram of scale scoring indicators in the survey. Responses categories for each issue above are: " $0-3$ " indicates low propensity, "4-6" indicates selective propensity and "7-10" indicates high propensity. The score ranges from 0 to 10 , with 0 indicating completely no, 1-3 indicating low propensity (the larger the scale score was in this part, the higher propensity for possibly was with "no add one", "no add two" "no add three"), 5 indicating possibly; 4-6 indicating selective propensity (possibly minus one, possibly minus add one), 7-9 indicating high propensity with certain influence (the larger the scale score was in this part, the higher propensity for completely yes was with "definitely minus three", "definitely minus two" "definitely minus one"), and 10 indicating definitely yes

nodes-positive become pregnant 5 years after surgery? And (4) Will you suggest patients who need endocrine therapy stop endocrine therapy 3 months before reproduction and continue after lactation? Third, we also took into account questions regarding the BRCA $1 / 2$ mutation, hormone drugs promoting ovulation and use of a multidisciplinary team (MDT). The questions were as follows: (1) would having a BRCA1/2 mutation patient affect your suggestions? (2) Would you suggest patients use hormone drugs to promote ovulation? (3) Would you agree to an MDT consultation to make a fully informed decision regarding the patients' reproduction?

Responses categories for each issue above are as follows: "0-3" indicates low propensity, "4-6" indicates selective propensity, and "7-10" indicates high propensity (Fig. 1). To improve test efficiency and reduce selection bias, item responses were fit by a graded item response model to create a latent scale. Therefore, different propensities of attitudes about physicians recommending breast cancer patients become reproduction are shown according to the scale value of different issues. Other physicians' measures included the following demographic information: sex, region, years of practice, number of outpatient breast cancer patients, frequency of academic forum participation, frequency of science popularization and propaganda activities about reproduction of early breast cancer, time spent answering issues, and frequency of offering advice to consult with experts in other subjects.

\section{Statistical analysis}

We first described the demographic characteristics of breast cancer-associated physicians and evaluated the reports of physicians recommending options for 11 specific clinical scenarios. Following the development of the 10-point scale for tendency of recommending reproduction, physicians were scored and categorized as having a low (" $0-3$ " indicate low propensity), selective ("4-6" indicate selective propensity) or high propensity ("7-10" indicate high propensity). Next, we used a multivariable linear regression model to confirm independent associations between the propensity of physicians' attitudes toward reproduction and physicians' specific demographic characteristics. All analyses were conducted using SPSS, version 23.0. All reported $P$ values were 2-sided with a 0.05 significance level.

\section{Results}

In total, 2000 breast cancer-associated physicians were invited and 1249 physicians responded (1249/2000, $62.35 \%)$, of which $911(911 / 1249,72.93 \%)$ were eligible according to the inclusion criteria that the minimum answer time was $90 \mathrm{~s}$ to adjust for an assumed time bias. 6 physicians were excluded because they did not want to be surveyed (Fig. 2).

\section{Characteristics of physicians}

Among 911 respondents (Table 1), 479 (52.6\%) were female physicians, and only 304 (33.4\%) physicians from developed areas. The proportion of physicians with less than 5 years of practice was the largest group (424 physicians, $46.5 \%)$ and the vast majority of respondents (756

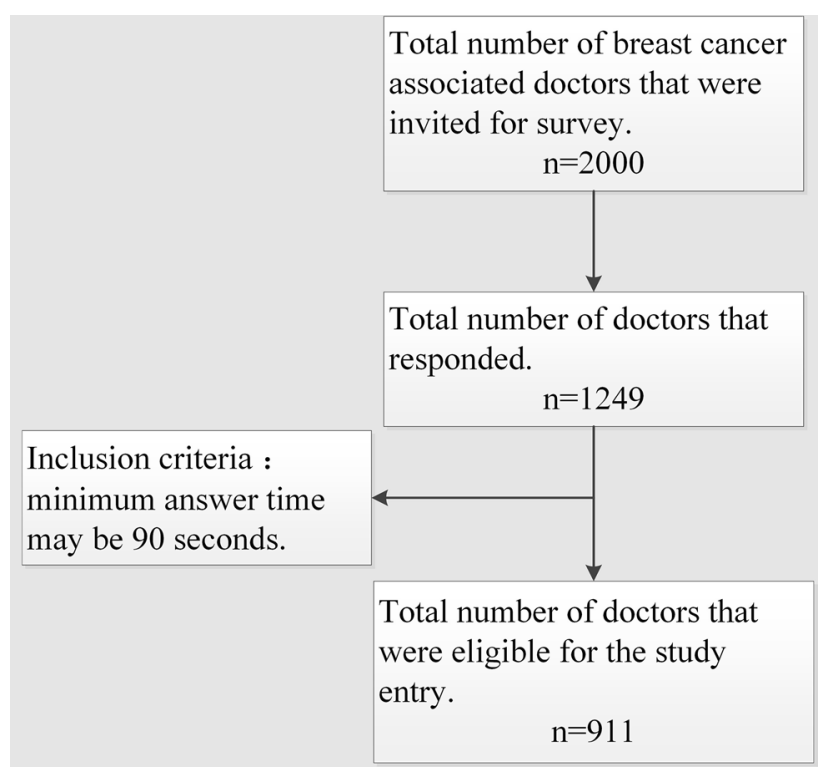

Fig. 2 The schematic diagram of investigation process 
Table 1 Breast cancerassociated physicians' sample characteristics $(N=911)$

\begin{tabular}{|c|c|}
\hline Characteristic & Value \\
\hline \multicolumn{2}{|l|}{ Gender, no. (\%) } \\
\hline Female & $479(52.6)$ \\
\hline Male & $432(47.4)$ \\
\hline \multicolumn{2}{|c|}{ Come from which area, no. $(\%)$} \\
\hline Developed area & $304(33.4)$ \\
\hline Underdeveloped area & $607(66.6)$ \\
\hline \multicolumn{2}{|l|}{ Years of practice, no. $(\%)$} \\
\hline$<5$ years & $424(46.5)$ \\
\hline 5 years $\sim$ & $285(31.3)$ \\
\hline 10 years $\sim$ & $202(22.2)$ \\
\hline \multicolumn{2}{|c|}{ Volume of breast cancer patients per outpatient service, no. (\%) } \\
\hline$<20$ & $431(47.3)$ \\
\hline $20 \sim$ & $325(35.7)$ \\
\hline $40 \sim$ & $95(10.4)$ \\
\hline$>60$ & $60(6.6)$ \\
\hline \multicolumn{2}{|c|}{ Times of participating in academic forum on breast cancer, no. (\%) } \\
\hline$<2$ & $148(16.2)$ \\
\hline $2-4$ & $391(42.9)$ \\
\hline $5-10$ & $275(30.2)$ \\
\hline$\geq 11$ & $97(10.6)$ \\
\hline \multicolumn{2}{|c|}{ Times of science popularization about reproduction of early breast cancer, no. (\%) } \\
\hline 0 & $278(30.5)$ \\
\hline 1 & $274(30.1)$ \\
\hline 2 & $185(20.3)$ \\
\hline$>2$ & $174(19.1)$ \\
\hline \multicolumn{2}{|c|}{$\begin{array}{l}\text { Times of consulting about reproduction problems after breast cancer surgery per outpatient service, no. } \\
(\%)\end{array}$} \\
\hline $1-2$ & $445(48.8)$ \\
\hline $3-4$ & $274(30.1)$ \\
\hline $5-6$ & $93(10.2)$ \\
\hline$>6$ & $99(10.9)$ \\
\hline \multicolumn{2}{|c|}{ Time spent solving the problem about reproduction in early breast cancer, no. (\%) } \\
\hline$<2 \min$ & $97(10.6)$ \\
\hline $2 \min \sim$ & $429(47.1)$ \\
\hline $6 \min \sim$ & $260(28.5)$ \\
\hline $11 \min \sim$ & 125 (13.7) \\
\hline
\end{tabular}

Of the initial 2000 breast cancer-associated physicians invited, 1249 physicians responded $(62.35 \%$ of those were invited) and 911 (72.93\% of those responded) were eligible according to the inclusion criteria that the minimum answer time may be $90 \mathrm{~s}$ to adjust for guaranteed time bias physicians, $83 \%$ ) show a volume of fewer than 40 breast cancer patients per outpatient service. A total of 372 $(40.8 \%)$ physicians expressed that they took part in more than five times academic conference per year. Regarding the popularization of breast cancer patient reproduction, 278 physicians $(30.5 \%)$ stated that they had never encountered the consultation about fertility with breast cancer patients. As the physicians' practice years increased, the number of physicians who had participated in academic forums more than 5 times and in popular science activities showed an increasing trend. The time physicians spend answering inquiries was mostly $(689,75.6 \%)$ between 2 and $10 \mathrm{~min}$.

\section{Physicians' attitude towards reproduction in young patients with early breast cancer}

As both the health of the mother and fetus need to be considered, $421(46.2 \%)$ and $249(27.3 \%)$ physicians thought reproduction had certain effects on patients and fetuses when breast cancer patients attempted reproduction (Fig. 3a and C $x=1$ and 2). In addition, in a scenario with BRCA-1/2 
A
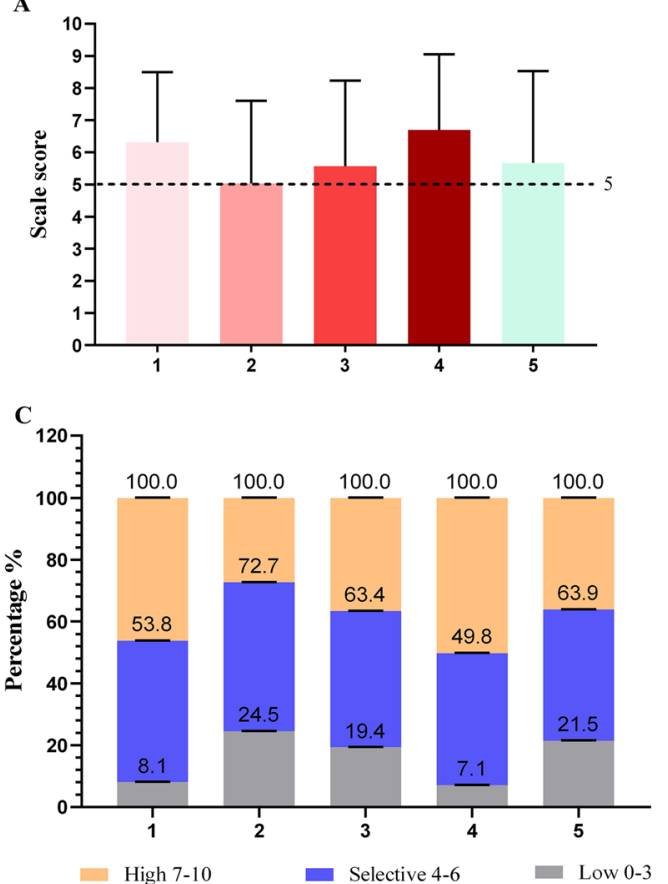

Fig. 3 Attitudes towards procreation of young patients with early breast cancer. a-d 1. Attitudes about pregnancy effects on breast cancer patients; 2. Attitudes about breast cancer patient's pregnancy's effects on the fetus. 3. Attitudes about effects on doctors' decisions because it is a BRCA1-related patient. 4. Attitudes about whether a patient with breast cancer may be pregnant. 5. Attitudes about whether patients may breastfeed after delivery. 6. Attitudes about patients with breast cancer in situ getting pregnant after the surgery and radiotherapy. 7. Attitudes about getting pregnant 2 years after surgery in invasive breast cancer patients with lymph nodes-negative. 8. Attitudes about getting pregnant 5 years after surgery in inva-

mutation patients, 734 (80.6\%) physicians would be influenced to help patient of making reproduction decisions (Fig. 3a and c, $x=3$ ). Regarding the most concerning topic of whether breast cancer patients could conceive, 65 (7.1\%) physicians having low and 457 (50.2\%) physicians having high propensity for recommending reproduction (Fig. 3a and c, $x=4)$. Physicians who responded to the issue whether patients may breastfeed after delivery, $196(21.5 \%)$ did not and $329(36.1 \%)$ did recommend breastfeeding (Fig. 3a and c, $x=5)$.

When the breast cancer patients become pregnant in different situation? For ductal carcinoma in situ (DCIS) after surgery and radiotherapy, $599(65.8 \%)$ physicians did not agree with the recommendation compared with 249 (27.3\%) who opted for selective recommendation and $63(6.9 \%)$ who highly recommended it (Fig. 3b and d, $x=6$ ). For 2 years after surgery in invasive breast cancer patients with lymph nodes-negative, $217(23.8 \%)$ physicians did not agree with the recommendation compared with $463(50.8 \%)$ who opted for selective recommendation and 231 (25.4\%) who
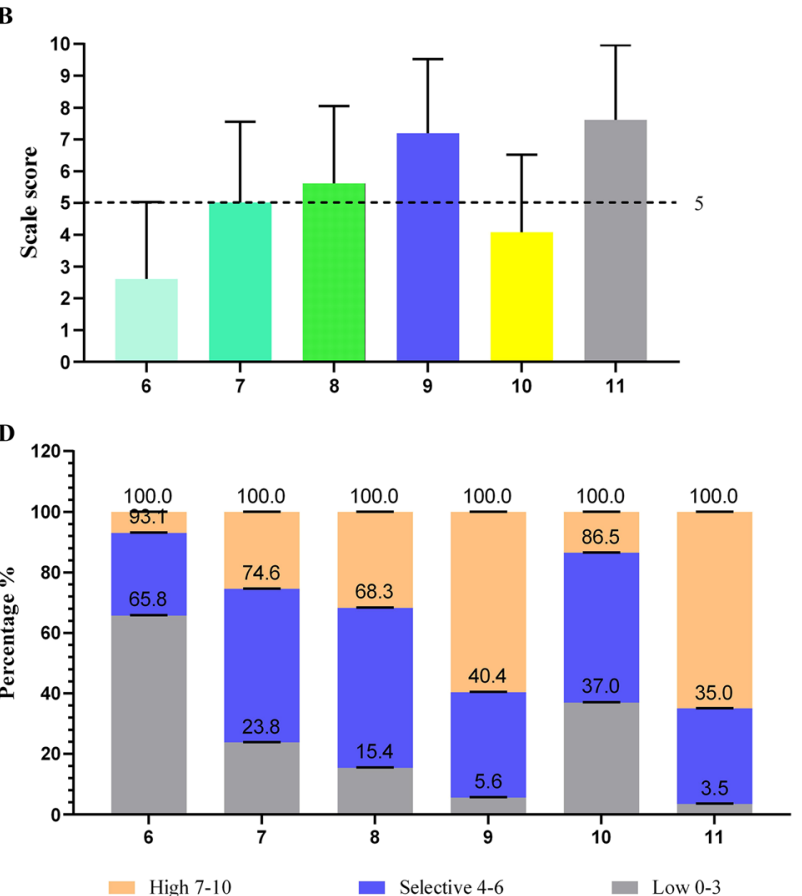

sive breast cancer patients with lymph nodes-positive. 9. Attitudes about whether the patients who need endocrinotherapy still need to continue endocrine treatment after lactation. 10. Attitudes about the using of hormone drugs to promote ovulation for patients with breast cancer. 11. Attitudes about agreement for an MDT consultation to make a full decision on the patients' procreation. Following the development of the 10-point scale of recommended reproductive tendency, doctors were scored and categorized as having low, selective or high propensity (" $0-3$ " indicate low propensity, " $4-6$ " indicate selective propensity and "7-10" indicate high propensity)

highly recommended it (Fig. $3 \mathrm{~b}$ and $\mathrm{d}, x=7$ ). For 5 years after surgery in invasive breast cancer patients with lymph nodes-positive, $140(15.4 \%)$ physicians did not agree with the recommendation compared with 482 (52.9\%) who opted for selective recommendation and 289 (31.7\%) who highly recommended it (Fig. 3b and d, $x=8$ ). Most physicians $(n=860,94.4 \%)$ indicated that patients who needed adjuvant endocrine therapy may continue to receive endocrine therapy after reproduction and lactation (Fig. $3 \mathrm{~b}$ and d, $x=9$, Table 5); There were 337 (37.0\%) physicians who did not recommend hormone drugs to promote ovulation, compared with $451(49.5 \%)$ who selectively agreed and $123(13.5 \%)$ who highly agreed (Fig. $3 \mathrm{~b}$ and d, $x=10$, Table 5). 32 (3.5\%) physicians did not agree with having an MDT consultation to make a fully informed decision on the patients' reproduction status (Fig. 3b and d, $x=11$, Table 5). A total of 861 (94.5\%) physicians stated that they advised the patients to consult experts from other disciplines, such as gynecology, oncology, genetic and psychology disciplines. 
Table 2 Multivariate analysis of factors that might influence breast cancer-associated physicians' attitudes about whether a patient with breast cancer may be pregnant. $(N=911)$

\begin{tabular}{|c|c|c|c|c|c|c|}
\hline \multirow[t]{2}{*}{ Factor } & \multicolumn{3}{|c|}{ Propensity, no } & \multirow[t]{2}{*}{ OR $(95 \% \mathrm{CI})$} & \multirow{2}{*}{$\begin{array}{l}\text { Wald } \\
P \text { value }\end{array}$} & \multirow[t]{2}{*}{$P$} \\
\hline & Low & Selective & High & & & \\
\hline Gender & & & & & & .007 \\
\hline Male & 27 & 166 & 239 & $1.44(1.11-1.89)$ & .007 & \\
\hline Female & 38 & 223 & 218 & Reference & & \\
\hline Come from which area & & & & & & .751 \\
\hline Developed area & 20 & 126 & 158 & $1.05(0.79-1.38)$ & .751 & \\
\hline Underdeveloped area & 45 & 263 & 299 & Reference & & \\
\hline Years of practice & & & & & & .662 \\
\hline$<5$ years & 40 & 190 & 194 & $0.95(0.66-1.37)$ & .788 & \\
\hline 5 years $\sim$ & 19 & 116 & 150 & $1.10(0.75-1.60)$ & .629 & \\
\hline 10 years $\sim$ & 6 & 83 & 113 & Reference & & \\
\hline Volume of breast cancer patients per outpatient service & & & & & & .748 \\
\hline$<20$ & 34 & 170 & 227 & $1.06(0.59-1.92)$ & .843 & \\
\hline $20 \sim$ & 22 & 156 & 147 & $0.91(0.51-1.63)$ & .748 & \\
\hline $40 \sim$ & 5 & 39 & 51 & $1.10(0.56-2.14)$ & .791 & \\
\hline$>60$ & 4 & 24 & 32 & Reference & & \\
\hline Times of participating in academic forum on breast cancer & & & & & & $<.001$ \\
\hline$<2$ & 20 & 74 & 54 & $0.22(0.12-0.41)$ & $<.001$ & \\
\hline $2-4$ & 24 & 187 & 180 & $0.41(0.24-0.68)$ & .001 & \\
\hline $5-10$ & 16 & 106 & 153 & $0.54(0.32-0.90)$ & .019 & \\
\hline$\geq 11$ & 5 & 22 & 70 & Reference & & \\
\hline Times of science popularization about reproduction of early breast cancer & & & & & & .272 \\
\hline 0 & 17 & 107 & 154 & $1.34(0.87-2.08)$ & .184 & \\
\hline 1 & 22 & 122 & 130 & $1.09(0.72-1.66)$ & .688 & \\
\hline 2 & 14 & 90 & 81 & $0.90(0.58-1.40)$ & .636 & \\
\hline$>2$ & 12 & 70 & 92 & Reference & & \\
\hline $\begin{array}{l}\text { Times of consulting about reproduction problems after breast cancer surgery } \\
\text { per outpatient service }\end{array}$ & & & & & & $<.001$ \\
\hline $1-2$ & 27 & 159 & 259 & $1.74(1.07-2.83)$ & .026 & \\
\hline $3-4$ & 23 & 150 & 101 & $0.88(0.54-1.43)$ & .594 & \\
\hline $5-6$ & 6 & 37 & 50 & $1.50(0.83-2.69)$ & .177 & \\
\hline$>6$ & 9 & 43 & 47 & Reference & & \\
\hline Time spent on solving the problem about reproduction in early breast cancer & & & & & & .022 \\
\hline$<2 \min$ & 11 & 39 & 47 & $0.63(0.35-1.11)$ & .107 & \\
\hline $2 \min \sim$ & 35 & 200 & 194 & $0.58(0.38-0.89)$ & .013 & \\
\hline $6 \min \sim$ & 9 & 113 & 138 & $0.88(0.56-1.38)$ & .573 & \\
\hline $11 \min \sim$ & 10 & 37 & 78 & Reference & & \\
\hline
\end{tabular}

\section{Multivariate analysis of factors that might influence physicians' attitudes on different issues}

We conducted a multivariate analysis of the factors that might influence physicians' attitudes on different issues. We identified several predictors of a more positive attitude toward reproduction (Table 2), including male (OR 1.44 [95\% CI, 1.11 to 1.89 ], $P=0.007$ ), more than 11 times of participating in academic forum on breast cancer (OR for less than 2 times: 0.22 [95\% CI, 0.12 to 0.41 ] $P<0.001$; OR for 2 to 4 times: 0.41 [95\% CI, 0.24 to 0.68 ], $P=0.001$; OR for 5 to 10 times: 0.54 [95\% CI, 0.32 to 0.90 ], $P=0.019$ ), 1-2 times of consulting about reproduction problems after breast cancer surgery per outpatient service (OR 1.74 [95\% CI, 1.07 to 2.83], $P=0.026$ ) and more than 11 min spending on solving the problem about reproduction in early breast cancer (OR for less than 2 min: 0.63 [95\% CI, 0.35 to 1.11], $P=0.107$; OR for 2 to $6 \mathrm{~min}: 0.58$ [95\% CI, 0.38-0.89], $P=0.013$; OR for 6 to $10 \mathrm{~min}: 0.88$ [95\% CI, 0.56 to 1.38 ], $P=0.573$ ). The only variable that was statistically significant 
Table 3 Multivariate analysis of factors that might influence breast cancer-associated physicians' attitudes about reproduction effects on breast cancer patients. $(N=911)$

\begin{tabular}{|c|c|c|c|c|c|c|}
\hline \multirow[t]{2}{*}{ Factor } & \multicolumn{3}{|c|}{ Propensity, no } & \multirow[t]{2}{*}{ OR $(95 \% \mathrm{CI})$} & \multirow{2}{*}{$\begin{array}{l}\text { Wald } \\
P \text { Value }\end{array}$} & \multirow[t]{2}{*}{$P$} \\
\hline & Low & Selective & High & & & \\
\hline Gender & & & & & & .132 \\
\hline Male & 45 & 194 & 193 & $0.82(0.63-1.06)$ & .132 & \\
\hline Female & 29 & 222 & 228 & Reference & & \\
\hline Come from which area & & & & & & .512 \\
\hline Developed area & 24 & 135 & 145 & $1.10(0.8-1.44)$ & .512 & \\
\hline Underdeveloped area & 50 & 281 & 276 & Reference & & \\
\hline Years of practice & & & & & & .482 \\
\hline$<5$ years & 30 & 195 & 199 & $1.03(0.73-1.47)$ & .854 & \\
\hline 5 years $\sim$ & 27 & 134 & 124 & $0.86(0.60-1.24)$ & .426 & \\
\hline 10 years $\sim$ & 17 & 87 & 98 & Reference & & \\
\hline Volume of breast cancer patients per outpatient service & & & & & & .378 \\
\hline$<20$ & 28 & 196 & 207 & $1.16(0.65-2.06)$ & .623 & \\
\hline $20 \sim$ & 31 & 154 & 140 & $0.90(0.51-1.59)$ & .715 & \\
\hline $40 \sim$ & 13 & 37 & 45 & $0.89(0.47-1.70)$ & .723 & \\
\hline$>60$ & 2 & 29 & 29 & Reference & & \\
\hline Times of participating in academic forum on breast cancer & & & & & & .010 \\
\hline$<2$ & 13 & 72 & 63 & $0.76(0.44-1.32)$ & .332 & \\
\hline $2-4$ & 30 & 199 & 162 & $0.85(0.54-1.36)$ & .500 & \\
\hline $5-10$ & 16 & 112 & 147 & $1.39(0.87-2.22)$ & .164 & \\
\hline$\geq 11$ & 15 & 33 & 49 & Reference & & \\
\hline Times of science popularization about reproduction of early breast cancer & & & & & & .863 \\
\hline 0 & 24 & 117 & 137 & $1.11(0.73-1.69)$ & .628 & \\
\hline 1 & 31 & 114 & 129 & $1.05(0.70-1.58)$ & .813 & \\
\hline 2 & 9 & 103 & 73 & $0.93(0.61-1.43)$ & .749 & \\
\hline$>2$ & 10 & 82 & 82 & Reference & & \\
\hline $\begin{array}{l}\text { Times of consulting about reproduction problems after breast cancer surgery } \\
\text { per outpatient service }\end{array}$ & & & & & & .389 \\
\hline $1-2$ & 49 & 183 & 213 & $0.75(0.46-1.21)$ & .233 & \\
\hline $3-4$ & 16 & 146 & 112 & $0.76(0.47-1.23)$ & .262 & \\
\hline $5-6$ & 4 & 43 & 46 & $1.05(0.59-1.87)$ & .862 & \\
\hline$>6$ & 5 & 44 & 50 & Reference & & \\
\hline Time spent on solving the problem about reproduction in early breast cancer & & & & & & .052 \\
\hline$<2 \min$ & 10 & 38 & 49 & $1.03(0.59-1.78)$ & .921 & \\
\hline $2 \min \sim$ & 29 & 196 & 204 & $1.01(0.67-1.52)$ & .958 & \\
\hline $6 \min \sim$ & 23 & 134 & 103 & $0.66(0.43-1.02)$ & .059 & \\
\hline $11 \min \sim$ & 12 & 48 & 65 & Reference & & \\
\hline
\end{tabular}

among physicians' attitudes about reproduction effects on breast cancer patients was times of participating in academic forum on breast cancer $(P=0.01$, Table 3$)$. Physicians who had been in practice for fewer than 5 years (OR 1.74 [95\% CI, 1.24-2.46], $P=0.001$ ) and more than 6 times of consulting about reproduction problems after breast cancer surgery per outpatient service (OR for 1 to 2 times: 0.45 [95\% CI, 0.28 to 0.72 ],$P=0.001$; OR for 3 to 4 times: 0.61 [95\% CI, 0.38-0.97], $P=0.038$; OR for 5 to 6 times: 0.91 [95\% CI, 0.52-1.58], $P=0.736$ ) were more likely to express high propensity attitude on effects of reproduction on fetuses $(P<0.01$; Table 4$)$. However, there is no significant variable on attitudes about physicians' decisions for BRCA-1/2 mutation patients (Table 5). While Table 6 shows that five variables were statistically significant among physicians who would and would not consider recommending patients breastfeeding after delivery, including gender, years of practice, times of participating in academic forum on breast cancer, times of science popularization about reproduction of early breast cancer and times of consulting about 
Table 4 Multivariate analysis of factors that might influence breast cancer-associated physicians' attitudes about breast cancer patient's reproduction's effects on the fetus. $(N=911)$

\begin{tabular}{|c|c|c|c|c|c|c|}
\hline \multirow[t]{2}{*}{ Factor } & \multicolumn{3}{|c|}{ Propensity, no } & \multirow[t]{2}{*}{ OR $(95 \% \mathrm{CI})$} & \multirow{2}{*}{$\begin{array}{l}\text { Wald } \\
P \text { value }\end{array}$} & \multirow[t]{2}{*}{$P$} \\
\hline & Low & Selective & High & & & \\
\hline Gender & & & & & & .181 \\
\hline Male & 127 & 191 & 114 & $0.84(0.65-1.08)$ & .181 & \\
\hline Female & 97 & 248 & 134 & Reference & & \\
\hline Come from which area & & & & & & .876 \\
\hline Developed area & 71 & 159 & 74 & $1.02(0.79-1.33)$ & .876 & \\
\hline Underdeveloped area & 153 & 280 & 174 & Reference & & \\
\hline Years of practice & & & & & & .004 \\
\hline$<5$ years & 83 & 216 & 125 & $1.74(1.24-2.46)$ & .001 & \\
\hline 5 years $\sim$ & 70 & 131 & 84 & $1.63(1.15-2.32)$ & .007 & \\
\hline 10 years $\sim$ & 71 & 92 & 39 & Reference & & \\
\hline Volume of breast cancer patients per outpatient service & & & & & & .743 \\
\hline$<20$ & 115 & 210 & 106 & $1.06(0.61-1.85)$ & .839 & \\
\hline $20 \sim$ & 70 & 157 & 98 & $1.23(0.71-2.13)$ & .470 & \\
\hline $40 \sim$ & 26 & 41 & 28 & $1.08(0.58-2.02)$ & .810 & \\
\hline$>60$ & 13 & 31 & 16 & Reference & & \\
\hline Times of participating in academic forum on breast cancer & & & & & & .854 \\
\hline$<2$ & 29 & 80 & 39 & $1.21(0.71-2.06)$ & .482 & \\
\hline $2-4$ & 87 & 204 & 100 & $1.03(0.66-1.62)$ & .894 & \\
\hline $5-10$ & 77 & 119 & 79 & $1.06(0.67-1.66)$ & .814 & \\
\hline$\geq 11$ & 31 & 36 & 30 & Reference & & \\
\hline Times of science popularization about reproduction of early breast cancer & & & & & & .076 \\
\hline 0 & 83 & 138 & 57 & $0.66(0.44-0.99)$ & .045 & \\
\hline 1 & 67 & 131 & 76 & $0.89(0.60-1.32)$ & .561 & \\
\hline 2 & 39 & 84 & 62 & $1.05(0.70-1.60)$ & .807 & \\
\hline$>2$ & 35 & 86 & 53 & Reference & & \\
\hline $\begin{array}{l}\text { Times of consulting about reproduction problems after breast cancer surgery } \\
\text { per outpatient service }\end{array}$ & & & & & & .001 \\
\hline $1-2$ & 143 & 200 & 102 & $0.45(0.28-0.72)$ & .001 & \\
\hline $3-4$ & 51 & 149 & 74 & $0.61(0.38-0.97)$ & .038 & \\
\hline $5-6$ & 14 & 46 & 33 & $0.91(0.52-1.58)$ & .736 & \\
\hline$>6$ & 16 & 44 & 39 & Reference & & \\
\hline Time spent on solving the problem about reproduction in early breast cancer & & & & & & .075 \\
\hline$<2 \min$ & 24 & 46 & 27 & $1.18(0.69-2.01)$ & .539 & \\
\hline $2 \min \sim$ & 92 & 219 & 118 & $1.16(0.78-1.71)$ & .467 & \\
\hline $6 \min \sim$ & 74 & 120 & 66 & $0.77(0.51-1.17)$ & .223 & \\
\hline $11 \min \sim$ & 34 & 54 & 37 & Reference & & \\
\hline
\end{tabular}

reproduction problems after breast cancer surgery per outpatient service.

On the three clinical situation gender was a significant variable (Tables 7, 8 and 9). In addition, times of consulting about reproduction problems was another variable that were statistically significant on situation $1(P=0.028$; Table 7), while time spent on solving the problem about reproduction was statistically significant on situation 2 $(P=0.020$; Table 8$)$. More variables were significant on situation 3 , including times of participating in academic forum on breast cancer, times of consulting about reproduction problems, time spent on solving the problem about reproduction (Table 9). In multivariate analysis, significant variables that might influence physicians' attitudes about whether the patients who need endocrinotherapy still need to continue endocrine treatment after lactation included times of participating in academic forum, times of science popularization about reproduction of early breast cancer, times of consulting about reproduction problems and time spent on solving the problem about reproduction 
Table 5 Multivariate analysis of factors that might influence breast cancer-associated physicians' attitudes about effects on physicians' decisions because it is a BRCA-1/2 mutation-related patient. $(N=911)$

\begin{tabular}{|c|c|c|c|c|c|c|}
\hline \multirow[t]{2}{*}{ Factor } & \multicolumn{3}{|c|}{ Propensity, no } & \multirow[t]{2}{*}{ OR $(95 \% \mathrm{CI})$} & \multirow{2}{*}{$\begin{array}{l}\text { Wald } \\
P \text { value }\end{array}$} & \multirow[t]{2}{*}{$P$} \\
\hline & Low & Selective & High & & & \\
\hline Gender & & & & & & .567 \\
\hline Male & 100 & 171 & 161 & $0.93(0.72-1.19)$ & .567 & \\
\hline Female & 77 & 229 & 173 & Reference & & \\
\hline Come from which area & & & & & & .605 \\
\hline Developed area & 52 & 143 & 109 & $1.07(0.83-1.39)$ & .605 & \\
\hline Underdeveloped area & 125 & 257 & 225 & Reference & & \\
\hline Years of practice & & & & & & .621 \\
\hline$<5$ years & 66 & 207 & 151 & $1.18(0.84-1.66)$ & .330 & \\
\hline 5 years $\sim$ & 57 & 123 & 105 & $1.13(0.80-1.60)$ & .495 & \\
\hline 10 years $\sim$ & 54 & 70 & 78 & Reference & & \\
\hline Volume of breast cancer patients per outpatient service & & & & & & .500 \\
\hline$<20$ & 84 & 195 & 152 & $1.00(0.58-1.74)$ & .998 & \\
\hline $20 \sim$ & 68 & 140 & 117 & $0.90(0.52-1.56)$ & .710 & \\
\hline $40 \sim$ & 16 & 37 & 42 & $1.27(0.68-2.37)$ & .453 & \\
\hline$>60$ & 9 & 28 & 23 & Reference & & \\
\hline Times of participating in academic forum on breast cancer & & & & & & .716 \\
\hline$<2$ & 26 & 75 & 47 & $1.09(0.65-1.85)$ & .747 & \\
\hline $2-4$ & 66 & 184 & 141 & $1.23(0.79-1.92)$ & .362 & \\
\hline $5-10$ & 53 & 118 & 104 & $1.25(0.80-1.95)$ & .332 & \\
\hline$\geq 11$ & 32 & 23 & 42 & Reference & & \\
\hline Times of science popularization about reproduction of early breast cancer & & & & & & .852 \\
\hline 0 & 66 & 113 & 99 & $0.91(0.61-1.36)$ & .633 & \\
\hline 1 & 51 & 123 & 100 & $1.03(0.69-1.52)$ & .897 & \\
\hline 2 & 26 & 93 & 66 & $1.06(0.70-1.59)$ & .799 & \\
\hline$>2$ & 34 & 71 & 69 & Reference & & \\
\hline $\begin{array}{l}\text { Times of consulting about reproduction problems after breast cancer surgery } \\
\text { per outpatient service }\end{array}$ & & & & & & .143 \\
\hline $1-2$ & 113 & 172 & 160 & $0.62(0.39-0.98)$ & .041 & \\
\hline $3-4$ & 41 & 139 & 94 & $0.72(0.45-1.15)$ & .164 & \\
\hline $5-6$ & 8 & 49 & 36 & $0.91(0.53-1.59)$ & .750 & \\
\hline$>6$ & 15 & 40 & 44 & Reference & & \\
\hline Time spent on solving the problem about reproduction in early breast cancer & & & & & & .568 \\
\hline$<2 \min$ & 21 & 40 & 36 & $0.98(0.58-1.65)$ & .925 & \\
\hline $2 \min \sim$ & 73 & 202 & 154 & $0.98(0.66-1.44)$ & .912 & \\
\hline $6 \min \sim$ & 53 & 117 & 90 & $0.80(0.53-1.21)$ & .285 & \\
\hline $11 \min \sim$ & 30 & 41 & 54 & Reference & & \\
\hline
\end{tabular}

(Table 10). There are four variable that were statistically significant among physicians who would and would not consider recommending patients with breast cancer using of hormone drugs to promote ovulation (Table 11). There are gender, years of practice, times of science popularization about reproduction of early breast cancer and times of consulting about reproduction problems after breast cancer surgery per outpatient service. There are four variables that were significant on physicians' agreement for a MDT consultation, including gender, times of participating in academic forum on breast cancer, times of science popularization about reproduction of early breast cancer and time spent on solving the problem about reproduction in early breast cancer (Table 12). 
Table 6 Multivariate analysis of factors that might influence breast cancer-associated physicians' attitudes about whether patients may breastfeed after delivery. $(N=911)$

\begin{tabular}{|c|c|c|c|c|c|c|}
\hline \multirow[t]{2}{*}{ Factor } & \multicolumn{3}{|c|}{ Propensity, no } & \multirow[t]{2}{*}{ OR $(95 \% \mathrm{CI})$} & \multirow{2}{*}{$\begin{array}{l}\text { Wald } \\
P \text { value }\end{array}$} & \multirow[t]{2}{*}{$P$} \\
\hline & Low & Selective & High & & & \\
\hline Gender & & & & & & .029 \\
\hline Male & 89 & 160 & 183 & $1.33(1.03-1.71)$ & .029 & \\
\hline Female & 107 & 226 & 146 & Reference & & \\
\hline Come from which area & & & & & & .297 \\
\hline Developed area & 55 & 134 & 115 & $1.15(0.88-1.50)$ & .297 & \\
\hline Underdeveloped area & 141 & 252 & 214 & Reference & & \\
\hline Years of practice & & & & & & $<.001$ \\
\hline$<5$ years & 112 & 198 & 114 & $0.52(0.37-0.74)$ & $<.001$ & \\
\hline 5 years $\sim$ & 55 & 118 & 112 & $0.78(0.55-1.11)$ & .169 & \\
\hline 10 years $\sim$ & 29 & 70 & 103 & Reference & & \\
\hline Volume of breast cancer patients per outpatient service & & & & & & .575 \\
\hline$<20$ & 98 & 162 & 171 & $1.14(0.65-1.99)$ & 653 & \\
\hline $20 \sim$ & 68 & 160 & 97 & $0.92(0.53-1.61)$ & .776 & \\
\hline $40 \sim$ & 20 & 36 & 39 & $1.04(0.55-1.96)$ & .904 & \\
\hline$>60$ & 10 & 28 & 22 & Reference & & \\
\hline Times of participating in academic forum on breast cancer & & & & & & $<.001$ \\
\hline$<2$ & 41 & 73 & 34 & $0.26(0.15-0.45)$ & $<.001$ & \\
\hline $2-4$ & 88 & 181 & 122 & $0.38(0.23-0.60)$ & $<.001$ & \\
\hline $5-10$ & 53 & 108 & 114 & $0.49(0.31-0.79)$ & .003 & \\
\hline$\geq 11$ & 14 & 24 & 59 & Reference & & \\
\hline Times of science popularization about reproduction of early breast cancer & & & & & & .013 \\
\hline 0 & 57 & 100 & 121 & $1.43(0.95-2.16)$ & .088 & \\
\hline 1 & 57 & 117 & 100 & $1.25(0.84-1.85)$ & .280 & \\
\hline 2 & 45 & 96 & 44 & $0.76(0.50-1.15)$ & .195 & \\
\hline$>2$ & 37 & 73 & 64 & Reference & & \\
\hline $\begin{array}{l}\text { Times of consulting about reproduction problems after breast cancer surgery } \\
\text { per outpatient service }\end{array}$ & & & & & & .040 \\
\hline $1-2$ & 88 & 160 & 197 & 1.57 (0.99-2.49) & .058 & \\
\hline $3-4$ & 58 & 153 & 63 & $1.07(0.67-1.71)$ & .775 & \\
\hline $5-6$ & 20 & 38 & 35 & $1.54(0.89-2.68)$ & .127 & \\
\hline$>6$ & 30 & 35 & 34 & Reference & & \\
\hline Time spent on solving the problem about reproduction in early breast cancer & & & & & & .335 \\
\hline$<2 \min$ & 24 & 44 & 29 & $0.90(0.53-1.54)$ & .707 & \\
\hline $2 \min \sim$ & 87 & 194 & 148 & $1.10(0.75-1.64)$ & 622 & \\
\hline $6 \min \sim$ & 53 & 107 & 100 & $1.33(0.88-2.02)$ & .175 & \\
\hline $11 \min \sim$ & 32 & 41 & 52 & Reference & & \\
\hline
\end{tabular}

\section{Discussion}

We conducted this study to determine breast cancer-associated physicians' treatment strategies and attitudes regarding reproduction for young patients with early breast cancer with specific clinical problems, and we conducted a multivariate analysis of physicians' characteristics that might influence their responses to different reproduction problems. To our knowledge, this is the first study to systematically survey breast cancer-associated physicians on this key issue.
In the survey, a total of 911/1249 (72.93\%) eligible physicians completed the questionnaire. We identified that male physicians had a more positive attitude toward reproduction, compared with the female physicians. This may be related to the fact that breast cancer patients are more likely to communicate with female physicians than male physicians. We found that $421(46.2 \%)$ physicians with a high propensity believed that reproduction had a definite impact on breast cancer patients and that $439(48.2 \%)$ physicians with a selective propensity stated that reproduction may have an impact 
Table 7 Multivariate analysis of factors that might influence breast cancer-associated physicians' attitudes about patients with breast cancer in situ getting pregnant after the surgery and radiotherapy. $(N=911)$

\begin{tabular}{|c|c|c|c|c|c|c|}
\hline \multirow[t]{2}{*}{ Factor } & \multicolumn{3}{|c|}{ Propensity, no } & \multirow[t]{2}{*}{ OR $(95 \% \mathrm{CI})$} & \multirow{2}{*}{$\begin{array}{l}\text { Wald } \\
P \text { value }\end{array}$} & \multirow[t]{2}{*}{$P$} \\
\hline & Low & Selective & High & & & \\
\hline Gender & & & & & & .025 \\
\hline Male & 272 & 126 & 34 & $1.38(1.04-1.83)$ & .025 & \\
\hline Female & 328 & 122 & 29 & Reference & & \\
\hline Come from which area & & & & & & .050 \\
\hline Developed area & 214 & 75 & 15 & $0.74(0.55-1.00)$ & .050 & \\
\hline Underdeveloped area & 386 & 173 & 48 & Reference & & \\
\hline Years of practice & & & & & & .832 \\
\hline$<5$ years & 280 & 116 & 28 & $0.90(0.61-1.32)$ & .578 & \\
\hline 5 years $\sim$ & 186 & 79 & 20 & $0.97(0.65-1.43)$ & .861 & \\
\hline 10 years $\sim$ & 134 & 53 & 15 & Reference & & \\
\hline Volume of breast cancer patients per outpatient service & & & & & & .173 \\
\hline$<20$ & 303 & 101 & 27 & $0.96(0.51-1.81)$ & .904 & \\
\hline $20 \sim$ & 197 & 105 & 23 & $1.37(0.74-2.55)$ & .319 & \\
\hline $40 \sim$ & 59 & 28 & 8 & $1.24(0.62-2.49)$ & .547 & \\
\hline$>60$ & 41 & 14 & 5 & Reference & & \\
\hline Times of participating in academic forum on breast cancer & & & & & & .092 \\
\hline$<2$ & 87 & 50 & 11 & $1.67(0.93-3.00)$ & .088 & \\
\hline $2-4$ & 256 & 113 & 22 & $1.09(0.66-1.80)$ & .746 & \\
\hline $5-10$ & 191 & 64 & 20 & $0.94(0.56-1.56)$ & .804 & \\
\hline$\geq 11$ & 66 & 21 & 10 & Reference & & \\
\hline Times of science popularization about reproduction of early breast cancer & & & & & & .273 \\
\hline 0 & 199 & 62 & 17 & $0.87(0.55-1.39)$ & 0.570 & \\
\hline 1 & 168 & 86 & 20 & $1.26(0.81-1.95)$ & 0.310 & \\
\hline 2 & 117 & 53 & 15 & $1.05(0.66-1.67)$ & 0.841 & \\
\hline$>2$ & 116 & 47 & 11 & Reference & & \\
\hline $\begin{array}{l}\text { Times of consulting about reproduction problems after breast cancer surgery } \\
\text { per outpatient service }\end{array}$ & & & & & & .028 \\
\hline $1-2$ & 318 & 100 & 27 & $0.80(0.48-1.35)$ & .408 & \\
\hline $3-4$ & 164 & 90 & 20 & $1.19(0.71-1.99)$ & .505 & \\
\hline $5-6$ & 53 & 30 & 10 & $1.59(0.87-2.90)$ & .128 & \\
\hline$>6$ & 65 & 28 & 6 & Reference & & \\
\hline Time spent on solving the problem about reproduction in early breast cancer & & & & & & .638 \\
\hline$<2 \min$ & 62 & 30 & 5 & $0.93(0.52-1.67)$ & .804 & \\
\hline $2 \min \sim$ & 289 & 113 & 27 & $0.77(0.50-1.20)$ & .247 & \\
\hline $6 \min \sim$ & 169 & 70 & 21 & $0.88(0.56-1.40)$ & .579 & \\
\hline $11 \min \sim$ & 80 & 35 & 10 & Reference & & \\
\hline
\end{tabular}

on the fetus. This might indicate that higher proportion of physician that reproduction has a greater impact on breast cancer patients. While previous study showing that reproduction did not affect survival in breast cancer patients [10]. Even so, when the patients with early breast cancer ask if she can get pregnant, only 457 (50.2\%) physicians in the study thought breast cancer patients may attempt to conceive. This suggests that the problem with physicians recommending reproduction is that they are not very confident. As well as, it was challenging for physicians to decide when may be the proper time for young patients to achieve reproduction based on their clinical situation.

Even though patients with breast cancer in situ may have a lower risk of recurrence, 599 (65.8\%) physicians do not recommend immediate reproduction after surgery or radiation, which is in contrast with the 2017 Rehabilitation Therapy Consensus on Breast Cancer in China. While the British Royal Society of Obstetrics and Gynecology recommends that this group of patients may attempt to become pregnant at least 6 months after treatment because of the toxicity of 
Table 8 Multivariate analysis of factors that might influence breast cancer-associated physicians' attitudes about getting pregnant 2 years after surgery in invasive breast cancer patients with lymph nodes-negative. $(N=911)$

\begin{tabular}{|c|c|c|c|c|c|c|}
\hline \multirow[t]{2}{*}{ Factor } & \multicolumn{3}{|c|}{ Propensity, no } & \multirow[t]{2}{*}{ OR $(95 \% \mathrm{CI})$} & \multirow{2}{*}{$\begin{array}{l}\text { Wald } \\
P \text { value }\end{array}$} & \multirow[t]{2}{*}{$P$} \\
\hline & Low & Selective & High & & & \\
\hline Gender & & & & & & $<.001$ \\
\hline Male & 87 & 206 & 139 & $1.83(1.42-2.37)$ & $<.001$ & \\
\hline Female & 130 & 257 & 92 & Reference & & \\
\hline Come from which area & & & & & & .848 \\
\hline Developed area & 67 & 167 & 70 & $0.98(0.75-1.27)$ & .848 & \\
\hline Underdeveloped area & 150 & 296 & 161 & Reference & & \\
\hline Years of practice & & & & & & .903 \\
\hline$<5$ years & 101 & 221 & 102 & $1.06(0.75-1.49)$ & .753 & \\
\hline 5 years $\sim$ & 69 & 142 & 74 & $1.09(0.76-1.55)$ & .652 & \\
\hline 10 years $\sim$ & 47 & 100 & 55 & Reference & & \\
\hline Volume of breast cancer patients per outpatient service & & & & & & .217 \\
\hline$<20$ & 115 & 203 & 113 & $0.65(0.37-1.15)$ & .138 & \\
\hline $20 \sim$ & 69 & 176 & 80 & $0.82(0.47-1.43)$ & .481 & \\
\hline $40 \sim$ & 23 & 52 & 20 & $0.62(0.33-1.16)$ & .133 & \\
\hline$>60$ & 10 & 32 & 18 & Reference & & \\
\hline Times of participating in academic forum on breast cancer & & & & & & .788 \\
\hline$<2$ & 37 & 76 & 35 & $0.80(0.47-1.36)$ & .405 & \\
\hline $2-4$ & 89 & 212 & 90 & $0.87(0.55-1.37)$ & .542 & \\
\hline $5-10$ & 67 & 138 & 70 & $0.81(0.52-1.27)$ & .355 & \\
\hline$\geq 11$ & 24 & 37 & 36 & Reference & & \\
\hline Times of science popularization about reproduction of early breast cancer & & & & & & .515 \\
\hline 0 & 68 & 136 & 74 & $0.82(0.54-1.23)$ & .339 & \\
\hline 1 & 69 & 139 & 66 & $0.80(0.53-1.18)$ & .259 & \\
\hline 2 & 45 & 97 & 43 & $0.73(0.48-1.11)$ & .141 & \\
\hline$>2$ & 35 & 91 & 48 & Reference & & \\
\hline $\begin{array}{l}\text { Times of consulting about reproduction problems after breast cancer surgery } \\
\text { per outpatient service }\end{array}$ & & & & & & .103 \\
\hline $1-2$ & 113 & 198 & 134 & $1.31(0.82-2.08)$ & .259 & \\
\hline $3-4$ & 61 & 167 & 46 & $0.94(0.59-1.50)$ & .790 & \\
\hline $5-6$ & 19 & 48 & 26 & $1.43(0.82-2.50)$ & .208 & \\
\hline$>6$ & 24 & 50 & 25 & Reference & & \\
\hline Time spent on solving the problem about reproduction in early breast cancer & & & & & & .020 \\
\hline$<2 \min$ & 21 & 45 & 31 & $1.59(0.93-2.71)$ & .091 & \\
\hline $2 \min \sim$ & 115 & 216 & 98 & $1.05(0.71-1.55)$ & .823 & \\
\hline $6 \min \sim$ & 45 & 145 & 70 & $1.55(1.03-2.36)$ & .038 & \\
\hline $11 \min \sim$ & 36 & 57 & 32 & Reference & & \\
\hline
\end{tabular}

radiotherapy and the need for postoperative endocrinology. For patients with invasive breast cancer, most physicians suggested that patients with negative lymph nodes may attempt reproduction 2 years after surgery, and patients with positive lymph nodes may attempt reproduction 5 years after surgery, which was consistent with the two guidelines above $[8,9]$. This suggests that the presence of carcinoma in situ or invasive carcinoma, lymph node metastasis, and postoperative time are factors influencing physicians' decisions regarding reproduction. However, in this study, we did not consider more factors, such as tumor size, pathological grade, invasion of peripheral vascular tumors and status of Her-2 and hormone receptor, into our analyses, which may be a deficiency in our survey.

In this survey, only 177 (19.4\%) physicians stated that they might not be influenced by BRCA-1/2 mutation-related patients. At present, the overall survival difference between BRCA-1/2 mutation-related patients who become pregnant and those who do not become pregnant may need to be explored. However, the differences in this issue were not 
Table 9 Multivariate analysis of factors that might influence breast cancer-associated physicians' attitudes about getting pregnant 5 years after surgery in invasive breast cancer patients with lymph nodes-positive. $(N=911)$

\begin{tabular}{|c|c|c|c|c|c|c|}
\hline \multirow[t]{2}{*}{ Factor } & \multicolumn{3}{|c|}{ Propensity, no } & \multirow[t]{2}{*}{ OR $(95 \% \mathrm{CI})$} & \multirow{2}{*}{$\begin{array}{l}\text { Wald } \\
P \text { value }\end{array}$} & \multirow[t]{2}{*}{$P$} \\
\hline & Low & Selective & High & & & \\
\hline Gender & & & & & & .003 \\
\hline Male & 57 & 218 & 157 & $1.48(1.14-1.91)$ & .003 & \\
\hline Female & 83 & 263 & 133 & Reference & & \\
\hline Come from which area & & & & & & .574 \\
\hline Developed area & 44 & 170 & 90 & $0.93(0.71-1.21)$ & .574 & \\
\hline Underdeveloped area & 96 & 311 & 200 & Reference & & \\
\hline Years of practice & & & & & & .185 \\
\hline$<5$ years & 72 & 230 & 122 & $1.07(0.75-1.51)$ & .711 & \\
\hline 5 years $\sim$ & 41 & 142 & 102 & $1.35(0.94-1.93)$ & .105 & \\
\hline 10 years $\sim$ & 27 & 109 & 66 & Reference & & \\
\hline Volume of breast cancer patients per outpatient service & & & & & & .270 \\
\hline$<20$ & 62 & 220 & 149 & $0.90(0.51-1.58)$ & .703 & \\
\hline $20 \sim$ & 55 & 176 & 94 & $0.75(0.43-1.32)$ & .323 & \\
\hline $40 \sim$ & 15 & 56 & 24 & $0.62(0.32-1.17)$ & .138 & \\
\hline$>60$ & 8 & 29 & 23 & Reference & & \\
\hline Times of participating in academic forum on breast cancer & & & & & & .005 \\
\hline$<2$ & 28 & 85 & 35 & $0.45(0.26-0.78)$ & .004 & \\
\hline $2-4$ & 72 & 210 & 109 & $0.57(0.36-0.90)$ & .017 & \\
\hline $5-10$ & 25 & 150 & 100 & $0.83(0.52-1.32)$ & .434 & \\
\hline$\geq 11$ & 15 & 36 & 46 & Reference & & \\
\hline Times of science popularization about reproduction of early breast cancer & & & & & & .507 \\
\hline 0 & 42 & 147 & 89 & $0.81(0.53-1.22)$ & .311 & \\
\hline 1 & 49 & 145 & 80 & $0.77(0.51-1.15)$ & .204 & \\
\hline 2 & 31 & 99 & 55 & $0.73(0.48-1.12)$ & .154 & \\
\hline$>2$ & 18 & 90 & 66 & Reference & & \\
\hline $\begin{array}{l}\text { Times of consulting about reproduction problems after breast cancer surgery } \\
\text { per outpatient service }\end{array}$ & & & & & & .034 \\
\hline $1-2$ & 64 & 216 & 165 & $1.52(0.95-2.45)$ & .081 & \\
\hline $3-4$ & 44 & 167 & 63 & $0.97(0.60-1.56)$ & .889 & \\
\hline $5-6$ & 14 & 50 & 29 & $1.17(0.66-2.06)$ & .587 & \\
\hline$>6$ & 18 & 48 & 33 & Reference & & \\
\hline Time spent on solving the problem about reproduction in early breast cancer & & & & & & .002 \\
\hline$<2 \min$ & 15 & 51 & 31 & $1.19(0.69-2.04)$ & .542 & \\
\hline $2 \min \sim$ & 75 & 242 & 112 & $0.90(0.60-1.34)$ & .588 & \\
\hline $6 \min \sim$ & 26 & 131 & 103 & $1.65(1.08-2.52)$ & .021 & \\
\hline $11 \min \sim$ & 24 & 57 & 44 & Reference & & \\
\hline
\end{tabular}

statistically significant among physicians' demographic characteristics, which indicated that most physicians may take the BRCA-1/2 mutation into consideration to help make decisions for patients.

Previous studies have shown that breastfeeding can reduce the risk of recurrence of breast cancer [11-13], and $329(36.1 \%)$ physicians in this study stated that breast cancer patients may definitely breastfeed after reproduction, which is consistent with the conclusion of the previous study. The British Royal Society of Obstetrics and Gynecology recommends breastfeeding on the unoperated side of the breast because the fibrosis caused by radiotherapy limits galactosis during breast-conserving surgery. Therefore, it's critical important to develop a practical guide of reproduction planning for young patients with early breast cancer and thus provide more reliable guidelines for the clinical practice.

The advantage of this study is that it is the first clinical research on the reproduction attitude towards the postoperative breast cancer patients. It is a large sample survey 
Table 10 Multivariate analysis of factors that might influence breast cancer-associated physicians' attitudes about whether the patients who need endocrinotherapy still need to continue endocrine treatment after lactation. $(N=911)$

\begin{tabular}{|c|c|c|c|c|c|c|}
\hline \multirow[t]{2}{*}{ Factor } & \multicolumn{3}{|c|}{ Propensity, no } & \multirow[t]{2}{*}{ OR $(95 \% \mathrm{CI})$} & \multirow{2}{*}{$\begin{array}{l}\text { Wald } \\
P \text { value }\end{array}$} & \multirow[t]{2}{*}{$P$} \\
\hline & Low & Selective & High & & & \\
\hline Gender & & & & & & .352 \\
\hline Male & 23 & 141 & 268 & $1.14(0.86-1.51)$ & .352 & \\
\hline Female & 28 & 176 & 275 & Reference & & \\
\hline Come from which area & & & & & & .960 \\
\hline Developed area & 14 & 108 & 182 & $0.99(0.74-1.33)$ & .960 & \\
\hline Underdeveloped area & 37 & 209 & 361 & Reference & & \\
\hline Years of practice & & & & & & .490 \\
\hline$<5$ years & 26 & 165 & 233 & $0.99(0.67-1.44)$ & .939 & \\
\hline 5 years $\sim$ & 11 & 97 & 177 & $1.19(0.80-1.77)$ & .396 & \\
\hline 10 years $\sim$ & 14 & 55 & 133 & Reference & & \\
\hline Volume of breast cancer patients per outpatient service & & & & & & .052 \\
\hline$<20$ & 18 & 136 & 277 & $1.28(0.70-2.35)$ & .418 & \\
\hline $20 \sim$ & 23 & 131 & 171 & $0.84(0.47-1.53)$ & .573 & \\
\hline $40 \sim$ & 7 & 27 & 61 & $1.30(0.65-2.58)$ & .455 & \\
\hline$>60$ & 3 & 23 & 34 & Reference & & \\
\hline Times of participating in academic forum on breast cancer & & & & & & $<.001$ \\
\hline$<2$ & 13 & 66 & 69 & $0.27(0.15-0.49)$ & $<.001$ & \\
\hline $2-4$ & 24 & 146 & 221 & $0.51(0.30-0.86)$ & .012 & \\
\hline $5-10$ & 8 & 85 & 182 & $0.79(0.46-1.35)$ & .395 & \\
\hline$\geq 11$ & 6 & 20 & 71 & Reference & & \\
\hline Times of science popularization about reproduction of early breast cancer & & & & & & .003 \\
\hline 0 & 15 & 81 & 182 & $1.60(1.02-2.52)$ & .043 & \\
\hline 1 & 13 & 90 & 171 & $1.63(1.05-2.53)$ & .030 & \\
\hline 2 & 19 & 76 & 90 & $0.83(0.53-1.29)$ & .396 & \\
\hline$>2$ & 4 & 70 & 100 & Reference & & \\
\hline $\begin{array}{l}\text { Times of consulting about reproduction problems after breast cancer surgery } \\
\text { per outpatient service }\end{array}$ & & & & & & $<.001$ \\
\hline $1-2$ & 20 & 116 & 309 & $1.46(0.88-2.42)$ & .143 & \\
\hline $3-4$ & 16 & 129 & 129 & $0.71(0.43-1.17)$ & .183 & \\
\hline $5-6$ & 10 & 36 & 47 & $0.66(0.37-1.19)$ & .165 & \\
\hline$>6$ & 5 & 36 & 58 & Reference & & \\
\hline Time spent on solving the problem about reproduction in early breast cancer & & & & & & .047 \\
\hline$<2 \min$ & 11 & 33 & 53 & $0.65(0.36-1.15)$ & .138 & \\
\hline $2 \min \sim$ & 18 & 165 & 246 & $0.88(0.57-1.36)$ & .552 & \\
\hline $6 \min \sim$ & 12 & 83 & 165 & $1.30(0.81-2.06)$ & .274 & \\
\hline $11 \min \sim$ & 10 & 36 & 79 & Reference & & \\
\hline
\end{tabular}

of breast cancer-associated physicians in China with a high response rate and that it enables understanding of the attitudes of breast physicians based on specific clinical scenarios. However, there are also some limitations. First, our sample is insufficient, it's only for Chinese population and lack of international data. Second, when design the questionnaire, we should consider more different scenarios in the same patient in different time from diagnosis and thus be more directly assess the physicians' recommendations on timing of reproduction. Third, there is no stratification of age stage and no specific investigation into different disciplines, including breast surgeons, breastfeeding consultants, rehabilitation specialists and Radiology Department. Most importantly, we relied on reports from breast 
Table 11 Multivariate analysis of factors that might influence breast cancer-associated physicians' attitudes about the using of hormone drugs to promote ovulation for patients with breast cancer. $(N=911)$

\begin{tabular}{|c|c|c|c|c|c|c|}
\hline \multirow[t]{2}{*}{ Factor } & \multicolumn{3}{|c|}{ Propensity, no } & \multirow[t]{2}{*}{ OR $(95 \% \mathrm{CI})$} & \multirow{2}{*}{$\begin{array}{l}\text { Wald } \\
P \text { Value }\end{array}$} & \multirow[t]{2}{*}{$P$} \\
\hline & Low & Selective & High & & & \\
\hline Gender & & & & & & $<.001$ \\
\hline Male & 144 & 216 & 72 & $1.64(1.27-2.13)$ & $<.001$ & \\
\hline Female & 194 & 236 & 49 & Reference & & \\
\hline Come from which area & & & & & & .345 \\
\hline Developed area & 108 & 155 & 41 & $1.14(0.87-1.49)$ & .345 & \\
\hline Underdeveloped area & 230 & 297 & 80 & Reference & & \\
\hline Years of practice & & & & & & .039 \\
\hline$<5$ years & 144 & 224 & 56 & $1.56(1.10-2.21)$ & .013 & \\
\hline 5 years $\sim$ & 113 & 130 & 42 & $1.25(0.88-1.80)$ & .219 & \\
\hline 10 years $\sim$ & 81 & 98 & 23 & Reference & & \\
\hline Volume of breast cancer patients per outpatient service & & & & & & .065 \\
\hline$<20$ & 180 & 201 & 50 & $0.69(0.39-1.22)$ & .198 & \\
\hline $20 \sim$ & 110 & 171 & 44 & $0.94(0.54-1.66)$ & .842 & \\
\hline $40 \sim$ & 29 & 47 & 19 & $1.15(0.61-2.18)$ & .665 & \\
\hline$>60$ & 19 & 33 & 8 & Reference & & \\
\hline Times of participating in academic forum on breast cancer & & & & & & 653 \\
\hline$<2$ & 55 & 83 & 10 & $0.77(0.45-1.33)$ & .347 & \\
\hline $2-4$ & 151 & 192 & 48 & $0.74(0.47-1.18)$ & .203 & \\
\hline $5-10$ & 98 & 139 & 38 & $0.80(0.51-1.27)$ & .344 & \\
\hline$\geq 11$ & 34 & 38 & 25 & Reference & & \\
\hline Times of science popularization about reproduction of early breast cancer & & & & & & $<.001$ \\
\hline 0 & 124 & 129 & 25 & $0.41(0.27-0.62)$ & $<.001$ & \\
\hline 1 & 99 & 144 & 31 & $0.55(0.37-0.83)$ & .004 & \\
\hline 2 & 68 & 91 & 26 & $0.50(0.33-0.77)$ & .001 & \\
\hline$>2$ & 47 & 88 & 39 & Reference & & \\
\hline $\begin{array}{l}\text { Times of consulting about reproduction problems after breast cancer surgery } \\
\text { per outpatient service }\end{array}$ & & & & & & .018 \\
\hline $1-2$ & 179 & 212 & 54 & $1.43(0.89-2.30)$ & .135 & \\
\hline $3-4$ & 91 & 156 & 27 & $1.37(0.85-2.21)$ & .198 & \\
\hline $5-6$ & 28 & 39 & 26 & $2.46(1.39-4.33)$ & .002 & \\
\hline$>6$ & 40 & 45 & 14 & Reference & & \\
\hline Time spent on solving the problem about reproduction in early breast cancer & & & & & & .708 \\
\hline$<2 \min$ & 42 & 46 & 9 & $0.99(0.57-1.70)$ & .966 & \\
\hline $2 \min \sim$ & 150 & 231 & 48 & $1.21(0.81-1.80)$ & .356 & \\
\hline $6 \min \sim$ & 94 & 124 & 42 & $1.12(0.74-1.71)$ & .592 & \\
\hline $11 \min \sim$ & 52 & 51 & 22 & Reference & & \\
\hline
\end{tabular}

physicians about whether they would encourage postoperative pregnancies in patients with breast cancer, and we did not actually have clinical data. In this study, only BRCA$1 / 2$ mutation-related, in situ carcinoma or invasive in situ carcinoma, lymph node metastasis and postoperative time were considered influencing factors for fertility decisionmaking, and the risk of disease metastasis, recurrence and prognosis of patients should also be systematically evaluated (e.g., tumor size, pathological grade, invasion of peripheral vascular tumors and status of Her- 2 and hormone receptor), the lack of which may be a deficiency in our survey. Actually, the key to the decision of reproduction attitude lies in the patients, in the later research, we should focus more on the patients' attitude. 
Table 12 Multivariate analysis of factors that might influence breast cancer-associated physicians' attitudes about agreement for a MDT consultation to make a full decision on the patients' reproduction. $(N=911)$

\begin{tabular}{|c|c|c|c|c|c|c|}
\hline \multirow[t]{2}{*}{ Factor } & \multicolumn{3}{|c|}{ Propensity, no } & \multirow[t]{2}{*}{ OR $(95 \% \mathrm{CI})$} & \multirow{2}{*}{$\begin{array}{l}\text { Wald } \\
P \text { Value }\end{array}$} & \multirow[t]{2}{*}{$P$} \\
\hline & Low & Selective & High & & & \\
\hline Gender & & & & & & .027 \\
\hline Male & 14 & 119 & 299 & $1.39(1.04-1.85)$ & .027 & \\
\hline Female & 18 & 167 & 294 & Reference & & \\
\hline Come from which area & & & & & & .116 \\
\hline Developed area & 4 & 92 & 208 & $1.28(0.94-1.74)$ & .116 & \\
\hline Underdeveloped area & 28 & 194 & 385 & Reference & & \\
\hline Years of practice & & & & & & .463 \\
\hline$<5$ years & 10 & 163 & 251 & $0.83(0.56-1.24)$ & .371 & \\
\hline 5 years $\sim$ & 13 & 77 & 195 & $1.01(0.66-1.54)$ & .970 & \\
\hline 10 years $\sim$ & 9 & 46 & 147 & Reference & & \\
\hline Volume of breast cancer patients per outpatient service & & & & & & .378 \\
\hline$<20$ & 17 & 119 & 295 & $1.24(0.66-2.34)$ & .502 & \\
\hline $20 \sim$ & 11 & 115 & 199 & $0.93(0.50-1.74)$ & .822 & \\
\hline $40 \sim$ & 3 & 31 & 61 & $0.96(0.47-1.95)$ & .909 & \\
\hline$>60$ & 1 & 21 & 38 & Reference & & \\
\hline Times of participating in academic forum on breast cancer & & & & & & .001 \\
\hline$<2$ & 10 & 56 & 82 & $0.33(0.17-0.61)$ & .001 & \\
\hline $2-4$ & 12 & 133 & 246 & $0.53(0.30-0.92)$ & .025 & \\
\hline $5-10$ & 7 & 76 & 192 & $0.75(0.43-1.31)$ & .307 & \\
\hline$\geq 11$ & 3 & 21 & 73 & Reference & & \\
\hline Times of science popularization about reproduction of early breast cancer & & & & & & $<.001$ \\
\hline 0 & 12 & 63 & 203 & $2.86(1.78-4.60)$ & $<.001$ & \\
\hline 1 & 10 & 73 & 191 & $2.58(1.64-4.07)$ & $<.001$ & \\
\hline 2 & 5 & 79 & 101 & $1.12(0.72-1.77)$ & .611 & \\
\hline$>2$ & 5 & 71 & 98 & Reference & & \\
\hline $\begin{array}{l}\text { Times of consulting about reproduction problems after breast cancer surgery } \\
\text { per outpatient service }\end{array}$ & & & & & & .062 \\
\hline $1-2$ & 14 & 110 & 321 & $1.54(0.92-2.57)$ & .098 & \\
\hline $3-4$ & 12 & 106 & 156 & $1.03(0.62-1.71)$ & .912 & \\
\hline $5-6$ & 0 & 33 & 60 & $1.57(0.85-2.91)$ & .150 & \\
\hline$>6$ & 6 & 37 & 56 & Reference & & \\
\hline Time spent on solving the problem about reproduction in early breast cancer & & & & & & .001 \\
\hline$<2 \min$ & 10 & 31 & 56 & $0.35(0.19-0.66)$ & .001 & \\
\hline $2 \min \sim$ & 15 & 143 & 271 & $0.57(0.35-0.91)$ & .020 & \\
\hline $6 \min \sim$ & 4 & 80 & 176 & $0.92(0.56-1.51)$ & .730 & \\
\hline $11 \min \sim$ & 3 & 32 & 90 & Reference & & \\
\hline
\end{tabular}

\section{Conclusions}

This study showed that attitudes towards reproduction of young breast cancer patients from physicians in China. Physicians had a high propensity for recommending reproduction. Compared with both guidelines (2017 Rehabilitation Therapy Consensus on Breast Cancer in China and the British Royal Society of Obstetrics and Gynecology) recommendation when to reproduce in different circumstances for breast cancer patients, physicians from China remained a relatively conservative attitude. Most physicians advised the patients to consult experts from other disciplines, such as gynecology, oncology, genetic and psychology disciplines.

Funding This study was supported by grants from the Foundation Project of Guangzhou University of Chinese Medicine (No. XKP2019002); National Natural Science Foundation of China (No. 81904206 and 81974571); Guangdong Natural Science Foundation (No. 2017A030313719). 
Open Access This article is licensed under a Creative Commons Attribution 4.0 International License, which permits use, sharing, adaptation, distribution and reproduction in any medium or format, as long as you give appropriate credit to the original author(s) and the source, provide a link to the Creative Commons licence, and indicate if changes were made. The images or other third party material in this article are included in the article's Creative Commons licence, unless indicated otherwise in a credit line to the material. If material is not included in the article's Creative Commons licence and your intended use is not permitted by statutory regulation or exceeds the permitted use, you will need to obtain permission directly from the copyright holder. To view a copy of this licence, visit http://creativecommons.org/licenses/by/4.0/.

\section{References}

1. Anders CK, Johnson R, Litton J et al (2009) Breast cancer before age 40 years. Semin Oncol 36:237-249

2. Peccatori F, Cinieri S, Orlando L, Bellettini G (2008) Subsequent pregnancy after breast cancer. Recent Results Cancer Res 178:57-67

3. Sankila R, Heinävaara S, Hakulinen T (1994) Survival of breast cancer patients after subsequent term pregnancy: "healthy mother effect". Am J Obstet Gynecol 170(3):818-823

4. Theriault RL, Litton JK (2011) Safety of pregnancy following breast cancer diagnosis: a meta-analysis of 14 studies. Breast Dis 47:74-83. https://doi.org/10.1016/j.yobg.2011.05.150

5. Theriault RL (2013) Prognostic impact of pregnancy after breast cancer according to estrogen receptor status: a Multicenter Retrospective study. Breast Dis 24(2):154-155. https://doi. org/10.1016/j.breastdis.2013.04.008
6. Peccatori FA, Azim HA Jr, Orecchia R, Hoekstra HJ, Pavlidis N, Kesic V, Pentheroudakis G (2013) ESMO guidelines working group. Cancer, pregnancy and fertility: ESMO clinical practice guidelines for diagnosis, treatment and follow-up. Ann Oncol 24:160-170

7. Stensheim H, Cvancarova M, Møller B, Fosså SD (2011) Pregnancy after adolescent and adult cancer: a population-based matched cohort study. Int J Cancer 129:1225-1226

8. Breast Cancer Professional Committee of China Anti Cancer Association (2017) Guidelines and norms of breast cancer diagnosis and treatment of China anti cancer association. Chin J Cancer. https://doi.org/10.19401/j.cnki.1007-3639.2017.09.004

9. British Royal Society of Obstetrics and Gynecology. Pregnancy and Breast Cancer Guideline (2011) Green-top guideline no. 12. Royal College of Obstetricians and Gynaecologists

10. Iqbal J, Amir E, Rochon PA et al (2017) Association of the timing of pregnancy with survival in women with breast cancer. JAMA Oncol 3:659-665

11. Lambertini M, Kroman N, Ameye L et al (2017) Long-term safety of pregnancy following breast cancer according to estrogen receptor status. JNCI: J Natl Cancer Inst 110:426-429

12. Lehman TA, Shaik M, Modali RV et al (2015) Abstract 860: effects of breastfeeding and oral contraception use on the risk of breast cancer recurrence: a multinational study. Can Res 75(15 Supplement):860-860

13. Mayor S (2015) Breast feeding reduces risk of breast cancer recurrence, study finds. BMJ 350(apr29 14):h2325-h2325

Publisher's Note Springer Nature remains neutral with regard to jurisdictional claims in published maps and institutional affiliations. 